\title{
Assessing the Impact of Smart Cities on Local E-government Research: A Bibliometric Study
}

\author{
Gonçalo Paiva Dias ${ }^{1 *}$ \\ 1 School of Technology and Management of Agueda (ESTGA) / Research Unit on Governance, Competitiveness and Public \\ Policies (GOVCOPP), University of Aveiro, PORTUGAL
}

*Corresponding Author: gpd@ua.pt

Citation: Dias, G. P. (2019). Assessing the Impact of Smart Cities on Local E-government Research: A Bibliometric Study. Journal of Information Systems Engineering \& Management, 4(2), em0097. https://doi.org/10.29333/jisem/5897

Published: August 29, 2019

\begin{abstract}
This article presents a bibliometric study on the impact of smart cities development on local e-government research. This is relevant because the concept of smart cities has evolved from being essentially focused on the management of the cities' infrastructures to include other aspects such as quality of life, economic growth, sustainability and participatory governance, thus partially overlapping the previously existing concept of local e-government. To inform the study, three sets of documents retrieved from the Scopus database were compared to what concerns the number of documents and citations, subject areas, and keywords: research documents addressing smart cities in general; research documents addressing local egovernment; and research documents addressing smart cities in the scope of e-government. The study concludes that the relevance of smart cities within local e-government research has grown to represent about $20 \%$ of the number of documents published annually in the field, and that this contributed to broaden the range of subjects dealt with in the area. Moreover, it is observable a tendency towards the study of new areas of research related to the benefits and, generally, the consequences of smart cities development on service delivery and governance at the local level.
\end{abstract}

Keywords: smart cities, e-government, local government, bibliometrics, open data

\section{INTRODUCTION}

Smart cities have become a hot research topic for academics in last decade, with the number of papers published annually in the subject, as listed in the Scopus database, rising from about two dozen in 2009 to near 5000 in 2018 (see Figure 1). In the same period, the concept of smart cities has evolved from being essentially focused on the use of Information and Communication Technologies (ICT) to efficiently manage the infrastructures of cities to be more comprehensive and include other aspects of urban development, such as quality of life, economic growth, sustainability and participatory governance (Albino, Berardi and Dangelico, 2015; Caragliu, Del Bo and Nijkamp, 2011; Chen, 2010; Dias, 2018; Gil-Garcia, Pardo and Nam, 2015; Maijer and Bolívar, 2016; Piro et al., 2014).

"This more comprehensive concept of smart cities has the potential to overlap the previously existing concept of local e-government, understood as the use of ICT to support government operations, provide government services, and engage citizens at the local level (Chen and Gant, 2001; Cook et al., 2002; Dias and Gomes, 2014; Edmiston, 2003). Taking this into consideration, it makes sense to study to what extent the exponential growth of smart cities research has impacted the related subject of local e-government research. The study presented in this article was previously presented in Dias (2019a) and contributes to the aforementioned purpose by means of a bibliometric analysis. 


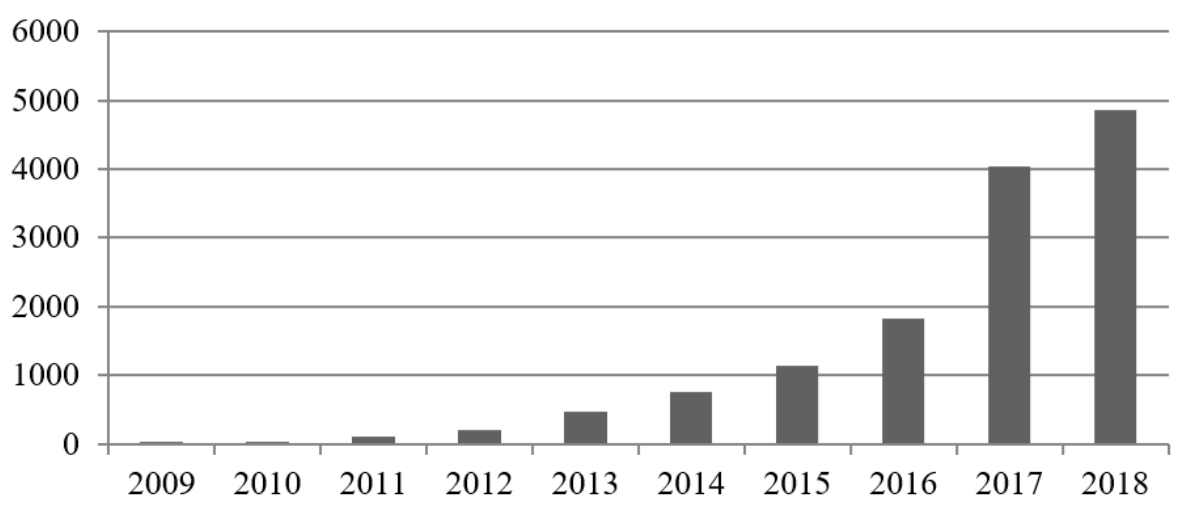

Figure 1. Evolution of the number of research documents published between 2009 and 2018 having the expressions 'smart city' or 'smart cities' in their title, abstract or keywords, while not having the expression 'egovernment' in the same fields, as retrieved from the Scopus database

Bibliometric analysis was selected as the methodology of the study because, although having important limitations, it has the advantage of allowing general conclusion about research production and impact on specific areas of knowledge without the burden of a thorough bibliographical review (Dias, 2018). The Scopus database was used because it typically retrieves more entries than other alternative sources when e-government studies are at stake (Dias, 2019b). No previous bibliometric analysis or bibliographic reviews on the topic of the interpenetration of Smart Cities with local e-government were identified in the literature.

Concerning the motivation and the methodological approach described above, this study will be guided by the following research question: Are smart cities reshaping local e-government research? To try to answer this question, three sets of documents retrieved from the Scopus database will be analyzed and compared: documents addressing smart cities in general; documents addressing local e-government; and documents addressing both subjects simultaneously. Specific analyzes and comparisons will include the evolution of documents published and citations received over time, the most relevant subject areas, and the most frequent keywords.

The remaining of this article is organized as follows: in the second section the methods are described, in the third section the results are presented and discussed and, finally, in the fourth section the conclusions and the future work are addressed.

\section{METHODS}

The bibliometric analysis that supports this study was based on data retrieved from the Scopus database the 19th February 2019. As described previously, three sets of documents were retrieved: documents addressing smart cities; documents addressing local e-government; and documents addressing both subjects simultaneously. The presence of specific expressions in the title, abstract or keywords of the documents were used as criterion for the selection of documents. Only documents published between 2009 and 2018 were retrieved.

To build the set of documents addressing the smart cities subject, all documents having the expressions 'smart city' or 'smart cities' and not having the expression 'e-government' were retrieved (see Expression 1). A total of 13,563 documents were retrieved using this search string.

TITLE-ABS-KEY ( $\{$ smart city\} OR \{smart cities\})

AND (PUBYEAR > 2008)

AND (PUBYEAR < 2019)

AND NOT TITLE-ABS-KEY (\{e-government $\}$ )

Concerning the set of documents addressing local e-government research, all documents having the expressions 'e-government' and simultaneously having one or more of the expressions 'local government', 'municipality', 'municipalities', 'city' or 'cities', while not having any of the expressions 'smart city' or 'smart cities', were retrieved (see Expression 2). A total of 1,350 documents were retrieved using this search string.

TITLE-ABS-KEY (\{e-government $\})$

AND (TITLE-ABS-KEY (\{local government $\}$ )

OR TITLE-ABS-KEY (municipality)

OR TITLE-ABS-KEY (municipalities)

OR TITLE-ABS-KEY (city)

OR TITLE-ABS-KEY (cities) )

AND ( PUBYEAR > 2008 )

AND ( PUBYEAR < 2019)

AND NOT (TITLE-ABS-KEY (\{smart city\})

OR TITLE-ABS-KEY (\{smart cities\})) 
Table 1. Documents and citations

\begin{tabular}{lccc}
\hline Global metrics & Smart cities & Local e-government & e-Government \& Smart cities \\
\hline Total documents & 13,435 & 970 & 128 \\
\hline Total citations & 54,536 & 5935 & 874 \\
\hline Average citations & 4.06 & 6.12 & 6.83 \\
\hline
\end{tabular}

- local e-government $\quad$ e-government \& smart cities

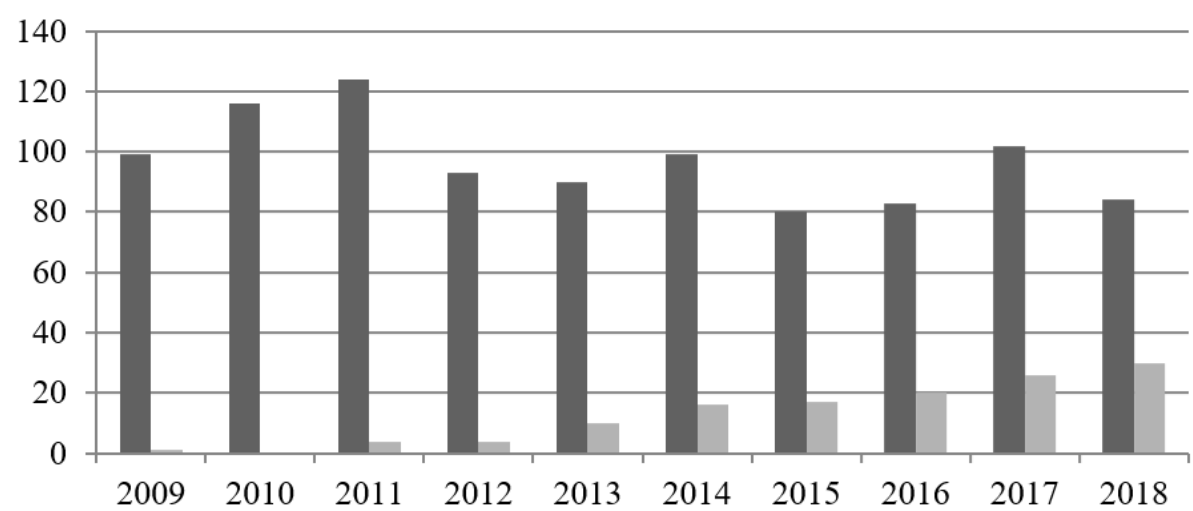

Figure 2. Evolution of the number of research documents addressing local e-government (excluding smart cities) and of documents addressing smart cities in the context of e-government, published between 2009 and 2018, as retrieved from the Scopus database

Finally, for the set of documents addressing both subject simultaneously, all documents having the expression 'e-government' and 'smart city' or 'smart cities' were retrieved (see Expression 3). A total of 129 documents were retrieved using this search string.

TITLE-ABS-KEY ( \{e-government $\}$ )

AND ( TITLE-ABS-KEY ( $\{$ smart city $\}$ )

OR TITLE-ABS-KEY ( $\{$ smart cities $\}))$

AND ( PUBYEAR > 2008 )

AND ( PUBYEAR < 2019)

The data was then analyzed using the Scopus web interface to produce information concerning the evolution of documents published and citations received over time, the most relevant subject areas, and the most frequent keywords. Only citations obtained until the end of 2018 were computed.

\section{RESULTS AND DISCUSSION}

The results of the bibliometric analysis are presented and discussed in the following three subsections, each one addressing a different perspective of analysis.

\section{Number of Documents and Citations}

Table 1 presents the global figures for documents published and citations received for each of the analyzed sets. These figures are complemented with the graphs in Figures 2 and 3 that show the evolution of documents published and citation received for documents addressing local e-government (excluding smart cities) and smart cities in the context of e-government, respectively. The evolution of documents published on the subject of smart cities (excluding e-government) is shown in Figure 1 and the number of citations received by those documents is shown in Figure 4.

As can be observed, average citation for documents addressing local e-government and addressing smart cities in the context of e-government are significantly higher than for documents addressing smart cities in other contexts. This happens despite both the growths of the number of documents published and citations received annually for smart cities (excluding e-government) being much sharper than in the cases of local e-government and of smart cities in the context of e-government. Thus, from this point of view, the observed behavior for documents addressing smart cities in the context of local e-government is closer to that of documents addressing local e-government than to that of documents addressing smart cities in general. 


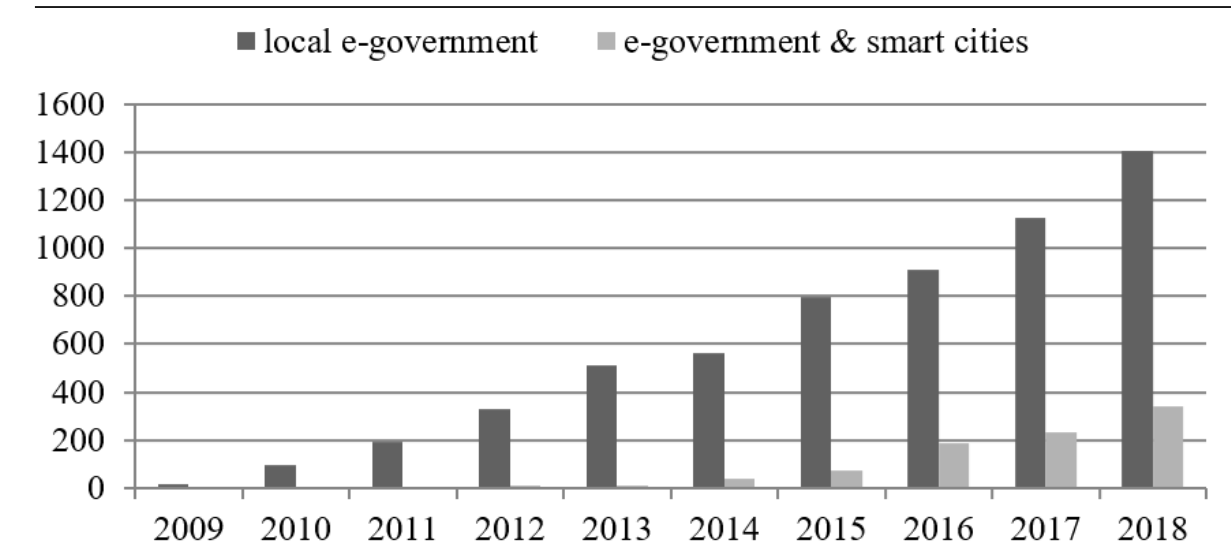

Figure 3. Evolution of the number of citations received by documents addressing local e-government (excluding smart cities) and by documents addressing smart cities in the context of e-government, published between 2009 and 2018, as retrieved from the Scopus database

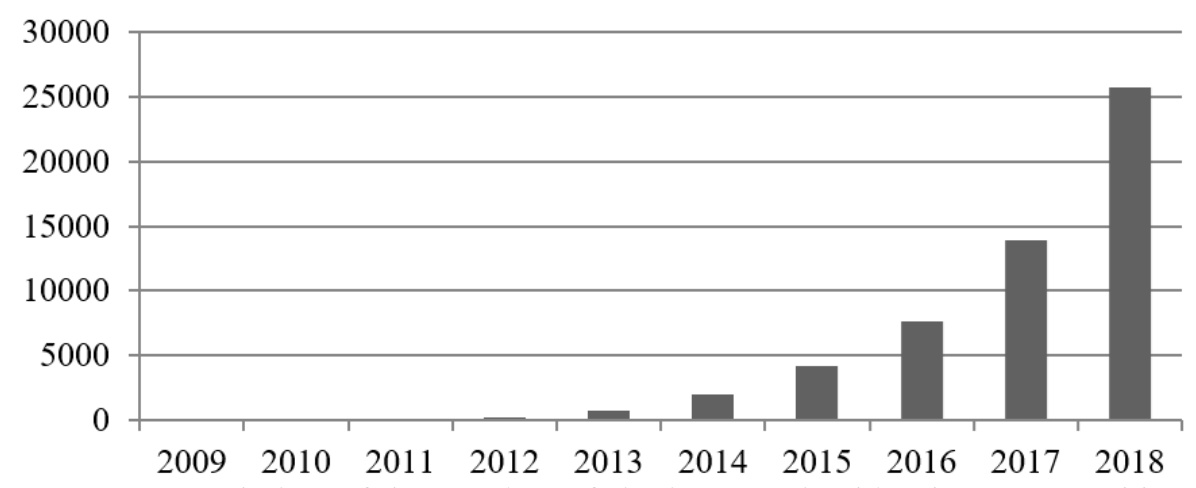

Figure 4. Evolution of the number of citations received by documents addressing smart cities in contexts other than e-government, published between 2009 and 2018, as retrieved from the Scopus database

Table 2. Main subject areas

\begin{tabular}{|c|c|c|c|}
\hline Subject areas & Smart cities & Local e-government & e-Government \& Smart cities \\
\hline Computer science & $70 \%$ & $61 \%$ & $79 \%$ \\
\hline Engineering & $39 \%$ & $12 \%$ & $18 \%$ \\
\hline Social sciences & $25 \%$ & $40 \%$ & $35 \%$ \\
\hline Mathematics & $14 \%$ & $8 \%$ & $16 \%$ \\
\hline Energy & $13 \%$ & $0 \%$ & $5 \%$ \\
\hline Decision sciences & $11 \%$ & $10 \%$ & $7 \%$ \\
\hline Environmental sciences & $8 \%$ & $2 \%$ & $4 \%$ \\
\hline Business, management and accounting & $5 \%$ & $22 \%$ & $8 \%$ \\
\hline
\end{tabular}

\section{Subject Areas}

Table 2 presents the percentage of documents of each set that is classified in each of the most relevant subject areas, as defined by Scopus. Only subject areas that include at least 5\% of the number of documents in at least one of the three sets of documents are represented in the Table. Note that documents are classified in subject areas according to the classification of the sources they were published in and, because a source can be classified in more than one subject area, the same document can also be classified in more than one subject area. In other words, subject areas are not mutually exclusive.

As can be observed in the Table, computer science is the most prominent subject area for all three sets of documents. Excluding this transversally prominent subject area, subject areas more oriented towards technology, the exact sciences or areas of application (engineering, mathematics, energy, environmental sciences) are more prominent for smart cities in general than for local e-government studies, while subject areas more oriented towards the social sciences (social sciences and business, management and accounting) are more prominent for local e-government than for smart cities studies.

As could be expected, for five of these six previously identified asymmetrically prominent subject areas (mathematics excluded), the documents that address smart cities in the scope of e-government exhibit intermediate percentages when compared to the two other sets of documents. Thus, when analyzed in light of subject areas, smart cities studies performed in the scope of e-government seem to inherit and combine trends that are 
Journal of Information Systems Engineering \& Management, 4(2), em0097

Table 3. Most frequent keywords

\begin{tabular}{|c|c|c|c|}
\hline Keywords & Smart cities & Local e-government & e-Government \& Smart cities \\
\hline Internet of things & $25.2 \%$ & $0.0 \%$ & $7.0 \%$ \\
\hline Big data & $14.0 \%$ & $0.9 \%$ & $7.8 \%$ \\
\hline Ubiquitous computing & $6.9 \%$ & $0.0 \%$ & $2.3 \%$ \\
\hline Information management & $4.3 \%$ & $4.7 \%$ & $5.5 \%$ \\
\hline Decision making & $3.7 \%$ & $4.2 \%$ & $6.3 \%$ \\
\hline Cloud computing & $3.6 \%$ & $0.9 \%$ & $6.3 \%$ \\
\hline Open data & $0.8 \%$ & $0.9 \%$ & $7.8 \%$ \\
\hline e-Services & $0.0 \%$ & $9.5 \%$ & $7.0 \%$ \\
\hline Public services & $0.0 \%$ & $5.4 \%$ & $3.9 \%$ \\
\hline e-Governance & $0.0 \%$ & $3.1 \%$ & $5.5 \%$ \\
\hline
\end{tabular}

characteristic of each of the two original universes, and can therefore be seen as a subarea that combines characteristics of the two main areas in which it can be classified.

\section{Most Frequent Keywords}

Table 3 lists the most common keywords in each of the document sets. This analysis is complementary to the one presented in the previous subsection in the sense that it can help to confirm if the study of smart cities in the context of e-government can be seen as a subarea which exhibits its own differentiated characteristics.

In the Table, only significate keywords are shown, meaning that obvious keywords such as 'smart cities', 'egovernment' or 'smart government' are not represented. Additionally, only keywords that occur in at least 5\% of the documents of at least one of the three sets of documents are included.

As can be observed, there are relevant differences between the most common keywords in the three sets of documents. Once again, as could be expected, smart cities research in the scope of e-government seems to share the most common keywords both with smart cities research in general (Internet of things, big data, ubiquitous computing, cloud computing) and with local e-government research (e-services, public services, e-governance). Note that these keywords are not otherwise shared between those two domains, at least with a relevant weight. On the contrary, information management and decision making constitute a common ground between smart cities and local e-government. Naturally, they are also relevant to smart cities research in the scope of e-government.

Still considering Table 3, it is interesting to note that 'open data' is the only keyword that assumes particular prominence for smart cities research in the scope of e-government and not for the two other sets of documents. This is probably because of the role that open data can have for transparency, the participation of citizens and the economic development of cities (typically local e-government desiderata) while it is highly dependent on the automatic production of data (typically facilitated by the development of smart cities). Thus, the frequency of this specific keyword might be an indication that there might be a core of specific subjects characterizing smart cities research in the scope of e-government. Indeed, Pereira et al. (2017), for example, defended that open data initiatives contribute to enhance the delivery of public value in smart city contexts.

\section{CONCLUSIONS AND FUTURE WORK}

This study aimed at finding to what extent the development of smart cities is reshaping local e-government research. The first relevant finding brought up by the study is that the investigation of smart cities in the scope of local e-government rose significantly since about a decade ago, currently accounting for about $20 \%$ of the documents published annually in the field. The same influence does not occur in the opposite direction, that is, the weight of e-government related documents in the total of documents addressing smart cities research is less than $1.5 \%$ and so, perfectly negligible. Thus, it makes sense to study the influence of smart cities development in the field of e-government, as is made in this article, but not vice versa.

Considering the results, and as could be expected, the research of smart cities in the scope of e-government constitutes a hinge between the two research areas, contributing to broaden the range of subjects that historically characterized local e-government research. Indeed, the publication of research papers in sources classified in subject areas such as engineering, mathematics, energy, and environmental sciences has become more frequent in the field of local e-government because of the raising interest of e-government researchers for smart cities. Also, the keyword analysis presented in this article allows the conclusion that keywords such as Internet of things, big data, ubiquitous computing, and cloud computing are becoming more frequent because of this recent local egovernment research trend.

But the research of smart cities in the scope of e-government also has the potential to address specific issues such as open data, for example, which, according to the results of this study, assumes a much greater prominence at the confluence of the two underlying areas than in each one of them in particular. Generalizing, the specific 
subject of smart cities research in the scope of e-government can explore new areas of research related to the benefits and, generally, the consequences that smart cities development may have for service delivery and the governance at the local level.

The study presented in this paper had an exploratory nature. Indeed, it constitutes a first investigation related to the presented research question. A deeper analysis of the subject will have to involve different and more informative methods. Amongst the possibilities, a systematic revision of the documents identified in this paper as addressing smart cities research in the scope of e-government would be of great value, namely because it would allow a deeper understanding of the specific subjects investigated in those studies and the methodologies used to investigate them. This is the future work that is expected to be developed following the one presented in this article.

\section{REFERENCES}

Albino, V., Berardi, U. and Dangelico, R. M. (2015). Smart Cities: Definitions, Dimensions, Performance, and Initiatives. Journal of Urban Technology, 22(1), 3-21. https://doi.org/10.1080/10630732.2014.942092

Caragliu, A., Del Bo, C. and Nijkamp, P. (2011). Smart Cities in Europe. Journal of Urban Technology, 18(2), 65-82. https://doi.org/10.1080/10630732.2011.601117

Chen, T. M. (2010). Smart Grids, Smart Cities Need Better Networks. IEEE Network, 24(2), 2-3. https://doi.org/10.1109/MNET.2010.5430136

Chen, Y. C. and Gant, J. (2001). Transforming local e-government services: the use of application service providers. Government Information Quarterly, 18(4), 343-355. https://doi.org/10.1016/S0740-624X(01)00090-9

Cook, M., LaVigne, M., Pagano, C., Dawes, S. and Pardo, T. (2002). Making a Case for Local e-Government. Albany, NY: Center for Technology in Government.

Dias. G. P. (2018). Smart cities research in Portugal and Spain: An exploratory biliometric analysis. In 2018 13th Iberian Conference on Information Systems and Tecbnologies (CISTI), pp. 1-6, IEEE. https:/ / doi.org/10.23919/CISTI.2018.8399295

Dias, G. P. (2019a). Are smart cities reshaping local e-government research? In 2019 14th Iberian Conference on Information Systems and Technologies (CISTI), pp. 1-4, IEEE. https://doi.org/10.23919/CISTI.2019.8760778

Dias, G. P. (2019b). Fifteen years of e-government research in Ibero-America: A bibliometric analysis. Government Information Quarterly, article in press. https://doi.org/10.1016/j.giq.2019.05.008

Dias, G. P. and Gomes, H. (2014). Evolution of local e-government maturity in Portugal. In 2014 9th Iberian Conference on Information Systems and Technologies (CISTI), pp. 1-5, IEEE. https://doi.org/10.1109/CISTI.2014.6877041

Edmiston, K. D. (2003). State and local e-government - prospects and challenges. American Review of Public Administration, 33, 10-45. https://doi.org/10.1177/0275074002250255

Gil-Garcia, J. R., Pardo, T. A. and Nam, T. (2015). What makes a city smart? Identifying core components and proposing an integrative and comprehensive conceptualization. Information Polity, 20(1), 61-87. https://doi.org/10.3233/IP-150354

Meijer, A. and Bolívar, M.P.R. (2016). Governing the smart city: a review of the literature on smart urban governance. International Review of Administrative Sciences, 82(2), 392-408. https:// doi.org/10.1177/0020852314564308

Pereira, G. V., Macadar, M. A., Luciano, E. M. and Testa, M. G. (2017). Delivering public value through open government data initiatives in a Smart City context. Information Systems Frontiers, 19(2), 213-229. https:// doi.org/10.1007/s10796-016-9673-7

Piro, G., Cianci, I., Boggia, G. and Camarda, P. (2014). Information centric services in Smart Cities. Journal of Systems and Software, 88(1), 169-188. https://doi.org/10.1016/j.jss.2013.10.029 